\begin{tabular}{|c|c|}
\hline 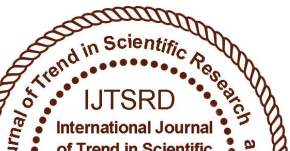 & $\begin{array}{l}\text { International Journal of Trend in Scientific } \\
\text { Research and Development (IJTSRD) }\end{array}$ \\
\hline $\begin{array}{lll} & \\
0\end{array}$ & International Open Access Journal \\
\hline and & ISSN No: $2456-6470$ | www.ijtsrd.com | Volume - 2 | Issue -3 \\
\hline
\end{tabular}

\title{
Application of An Expert System for Assessment and Evaluation of Higher Education Courses to identify Fast and Slow Learners
}

\author{
Mr. A. A. Govande \\ Assistant Professor, \\ V. P. Institute of Management Studies \& Research, \\ Sangli, Maharashtra, India
}

\author{
Dr. R. V. Kulkarni \\ Professor \& Head, Shahu Institute of Business \\ Education \& Research (SIBER), Kolhapur, \\ Maharashtra, India
}

\begin{abstract}
This article is based on design and development of An Expert System for Higher Education Courses. The aims of this system are to assess and evaluate the students by considering Scholastics and Non Scholastic aspects and to identify fast and slow learners based on the performance of students.
\end{abstract}

Keywords: Expert System, Assessment, Evaluation, Scholastic, Non-scholastic

\section{INTRODUCTION:}

Teachers and students are familiar with words such as examinations, tests, correction of question papers and results. All this has to do with finding out how much a student has learnt. An educational system which does not lay a balanced emphasis on all the three aspects namely, cognitive, affective and psychomotor is likely to produce imbalance in the personality of the student. In actual practice schools and colleges confine themselves to the cognitive development of students committed to their care. Even in regard to cognitive development, schools and colleges are very selective and undertake only scholastic programmes which can be easily dealt with either through the oral method of teaching or through the medium of textbook. The most important constituent of cognitive development is the development of the power of discrimination. But before discriminating the students based on their performance in a test, very first questions asked in the tests are require to be discriminate, the discrimination of question means identifying whether the question has power to discriminate or not. So by considering this factor the proposed system i.e. Expert System for
Assessment and Evaluation is designed to assess and evaluate the students, to discriminate the questions of each test and there by identifying fast and slow learners. The system provides platform to register College, Course, Student, to add subjects, Tests. Then by applying the algorithm, based on the performance of the student in selected subject system will generate the list of Fast Learners and Slow Learners.

\section{Objectives of System:}

1) To provide a platform to register College, Course, Student, to add subjects

2) To generate Tests and to add the questions

3) To store the performance evaluation details of the students

4) To evaluate Student based on scholastics and Non Scholastics aspects

5) To identify the fast and slow learners.

\section{Platform Used to Design System:}

Expert system for Assessment and Evaluation is developed using Visual Studio.NET 2010 framework. Developed system using Windows Application and preferred C\#.NET language to code.

\section{System Analysis:}

\section{Algorithm for Assessment and Evaluation System}

Step 1: Start

Step 2: Select Class 
Step 3: Select Subject

Step 4: Prepare a null set $\mathrm{T}_{\mathrm{F}}$ for fast learners and set $\mathrm{T}_{\mathrm{L}}$ for slow learner respectively

Step 5: Select Test

Step 6: Select first Item

Step 7: Arrange the test paper from the highest score to lower score

Step 8: From the ordered set of papers, make two groups: Put these with the highest scores in one group and those with the lowest scores in the other group. If 40 students are there then place the best $27 \%$ in Higher Ability Group (HAG) and the poorest 27\% in the other group i.e. Lower Ability Group(LAG)

Step9: For each item, compute the percentage of students who get the item right. This is called facility value.

Formula for item

$\mathbf{F} . \mathbf{V}=(\mathbf{R} / \mathbf{T}) * 100$

Where,

$\mathbf{R}=$ number of students scoring it right

$\mathbf{T}=$ total number who attempted it.

E.g. Taking HAG and LAG of 40 students, 18 of them have answered it rightF.V. $=(18 / 40)=0.45$

(RO1 Post Graduate Programmes Assessment \& Evaluation (2008), Yashwantarao IC Chavan Maharashtra, Page No. 57, 58)

Step 10: If $(\mathbf{F} . \mathbf{V}<\mathbf{0 . 5})$ then go to next step otherwise select next item and go to step 7

Step 11: Compute Discrimination Index, to check ability of question (i.e.item) to discriminate between the Higher Ability Students and Lower Ability Students. Discrimination is usually measured by the correlation between the score on the item and the score on the total test. Calculate Discrimination Index using following formula:

$\mathrm{D}=($ HAG-LAG $) * \mathbf{2} / \mathbf{1 0 0}$

Where,

HAG $=33 \%$ of students answering the item correctly in the Higher Ability Group

$\mathbf{L A G}=33 \%$ of students answering the item correctly in the Lower Ability Group
(RO1 Post Graduate Programmes Assessment \& Evaluation (2008), Yashwantarao Chavan Maharashtra, Page No. 57, 58)

Step 12: If $(\mathbf{D . I}<\mathbf{0 . 5})$ then prepare set $\mathrm{S}_{\mathrm{F}}$ from Higher Ability Group as set of Fast Learners and

$\mathrm{S}_{\mathrm{L}}$ from Lower Ability Group as set of Slow learners. Find $\mathbf{T}_{\mathbf{F}} \cap \mathbf{S}_{\mathbf{F}}$ and $\mathbf{T L} \cap \mathbf{S L}$. Make set $\mathrm{S}_{\mathrm{F}}$ and $\mathrm{S}_{\mathrm{L}}$ null. Else go to next step

Step 13: If next item presents go to step 7

Step 14: If next test presents then go to step 6

Step 15: If next subject presents then go to step 4

Step 16: Display elements of $\mathbf{T}_{\mathbf{F}}$ and $\mathbf{T}_{\mathbf{L}}$

Step 17: If next Class presents then go to step 3

Step 18: Stop

\section{Input Design:}

\section{Name :- Main Page}

Description :- This is the main page of the system. Different tabs are there like Registration, Create Test, Assessment Evaluation, Reports and Exit. If Registration menu gets clicked then its displays sub menus like Collge Registration, Student Registration and Admin Registration. Also in under Collge Registration there are two sub menus to Create Course and Adding Subjects to approprite created courses.

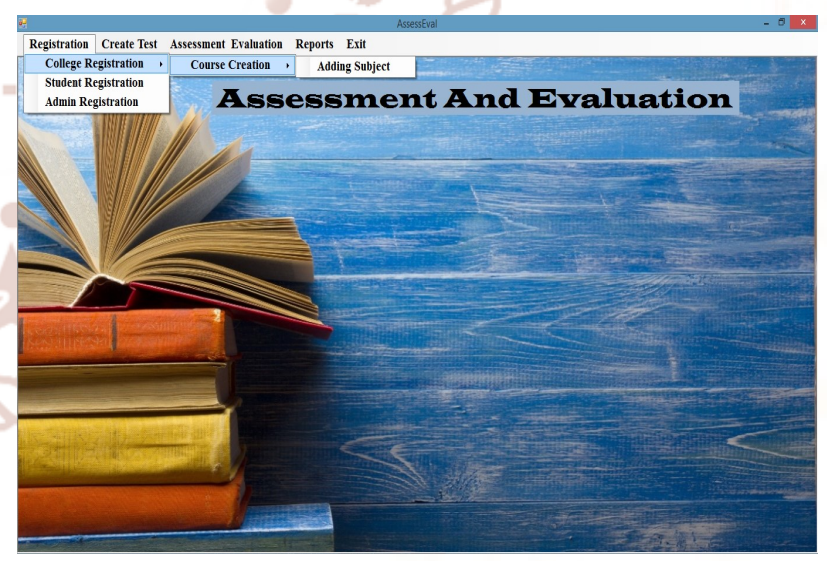

Name :- College Registration

Description :- This displays College Registration form, to specify and store collge details, like Name, Address, Affiliation Status etc. 


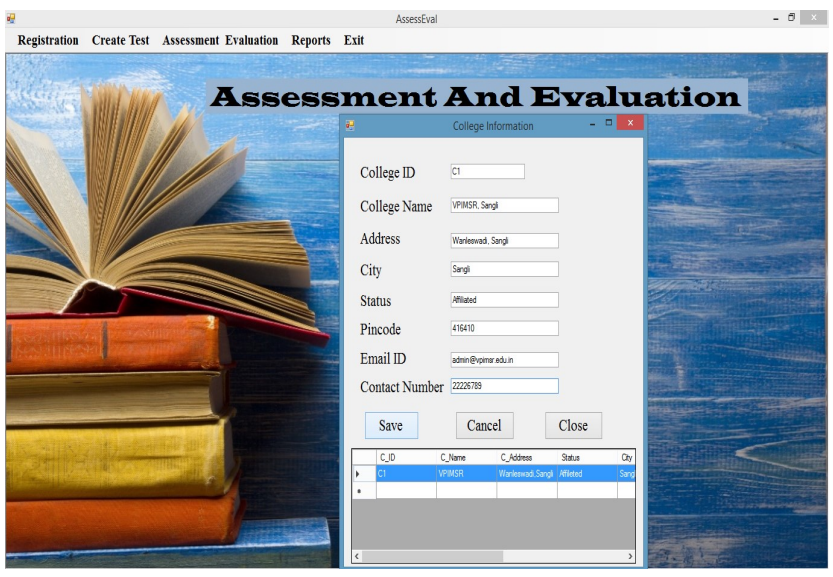

Name

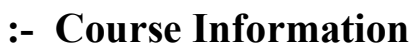

Description :- This is Course Information Form, to create various courses running in a perticular College.

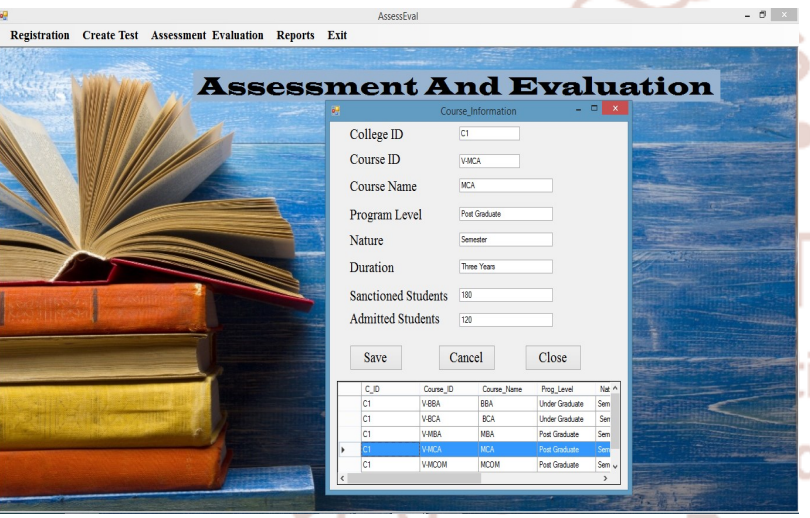

\section{Name :- Student Information}

Description :- This is Student Information Form to register Students for a Course they have admitted.

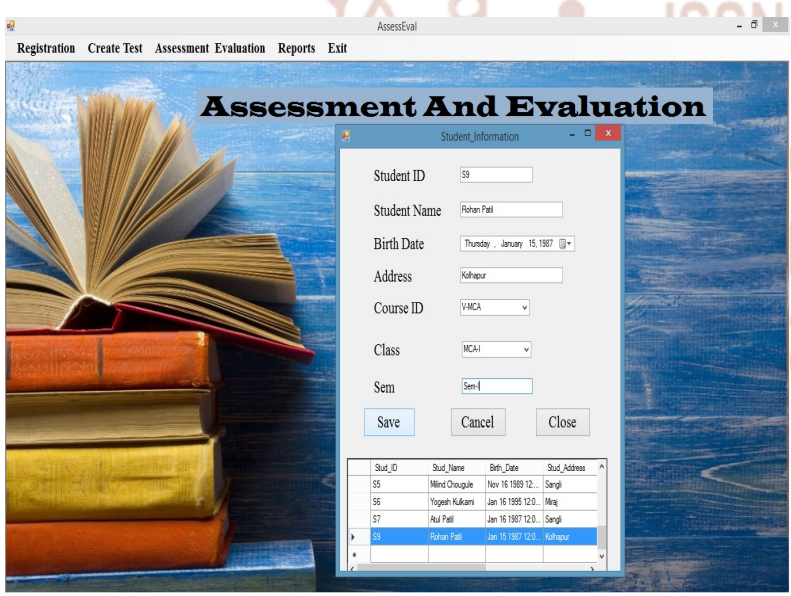

\section{Name :- Subject Information}

Description :- This is Subject Information Form, a sub menu under Course Registration. After creating course one can add number of subjects to that course.

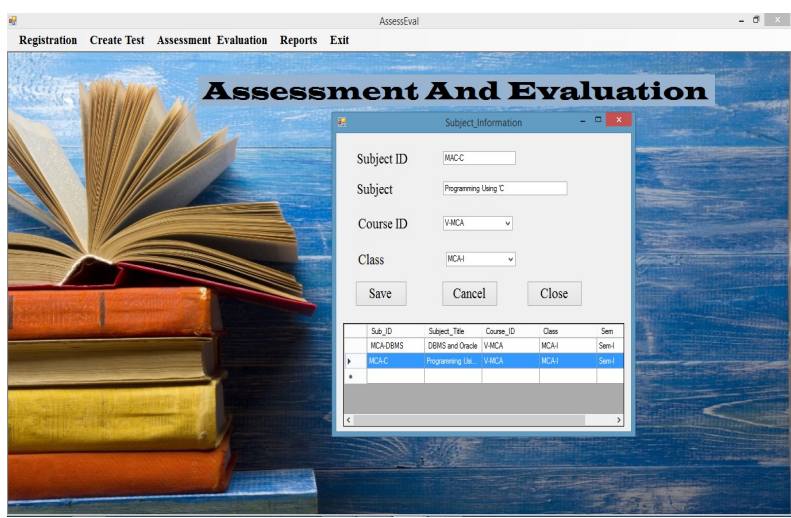

Name :- Create Tests

Description :- Create Test menu contains Category Information, Test Creation as sub menus. And Test Creation menu again contains two sub menus as Create Test and Add Question

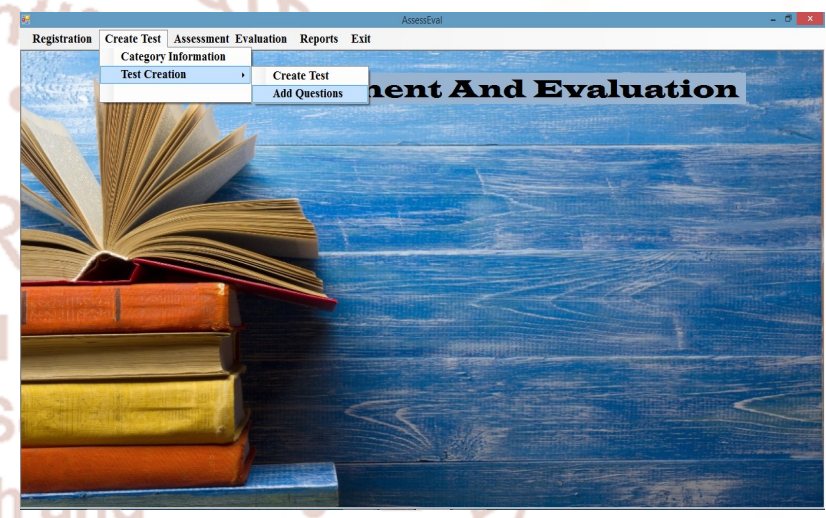

\section{Name :- Test_Q_Entry}

Description :- Following Screen displying Test Question Entry Form to enter various questions for a specific test of selected subject. To add question test is required to be created first.

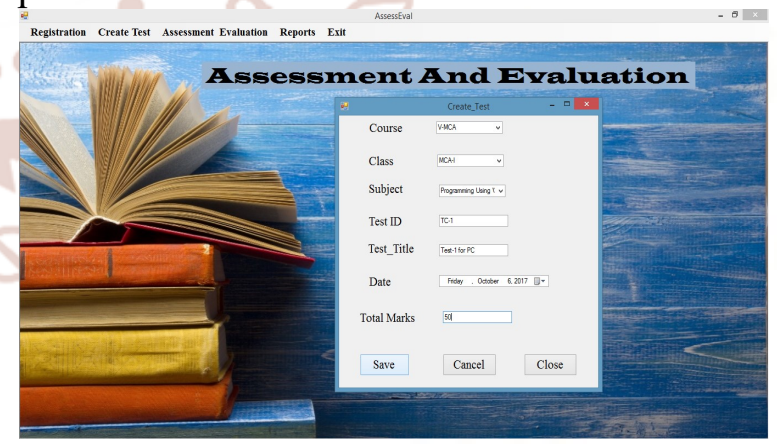

\section{Name :- Create Tests}

Description :- This screen shows the Create Test Form. This form is mainly to create Tests for a perticular subject. 


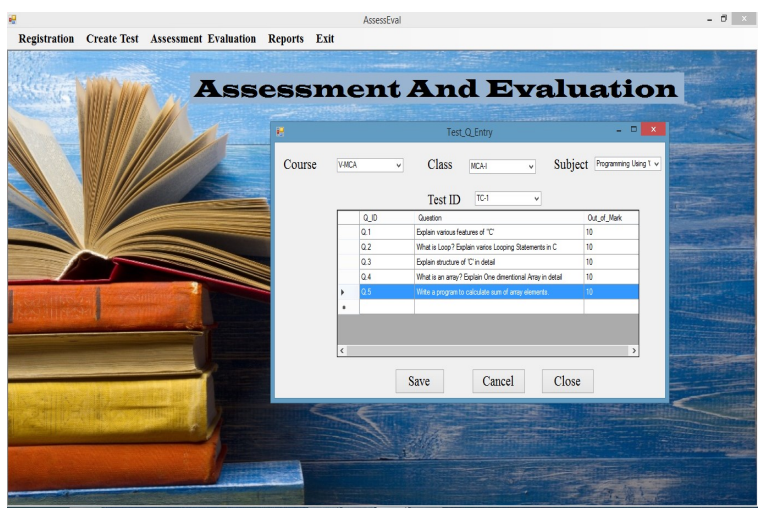

\section{Output Design}

Name :- Fast \& Slow Learners

Description :- This form displays the overall collective list of Fast and Slow Learner students based on the performance of the students in all the tests of selected subject. This form will display. Fisrt of all Couse is required to select then class and then subject, afterwords Fast and Slow learner Students will gets displayed in two different List Boxes.

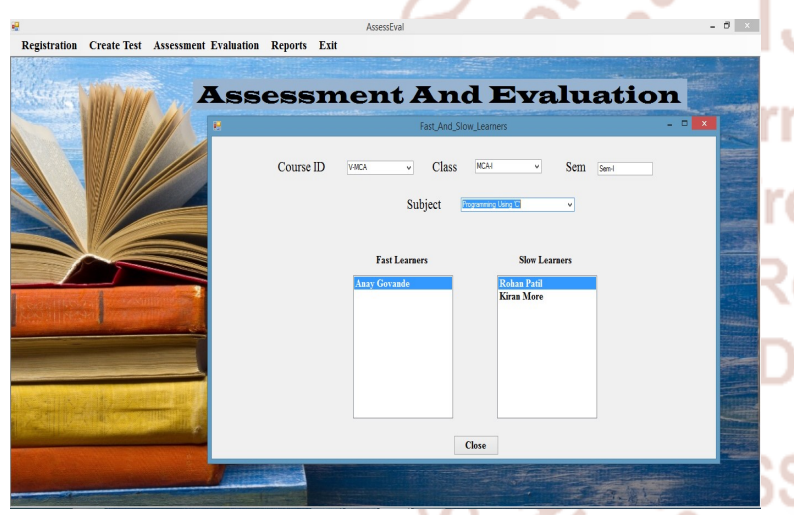

\section{Conclusion:}

Evaluation deals with the collection of evidences regarding changes which occur in the learner's behavior during the teaching learning process. Based on these evidences, interpretation and judgment, the progress of the learner is arrived at and decisions taken. The proposed expert system evaluates students based on their performance in each subject, and directly identifies the overall list of Fast learners and Slow learners.

\section{References:}

1) RO1 Post Graduate Programmes Assessment \& Evaluation (2008), Yashwantarao Chavan Maharashtra.

2) Jeffrey R. Shapiro: Visual Basic.Net: The Complete Reference Mcgraw Higher Edition

3) Herbert Schildt(2010): C\# 4.0: The Complete Reference, $4^{\text {th }}$ Edition: Mcgraw Higher Edition

4) Halliwell S. (1992.) Teaching English in the Primary Classroom. Longman, Singapore.

5) Hawkins, J. (2009). "Internal and external quality assurance: il implication for learning and accreditation: some observations from the University $\mathrm{C}$ of California", Proceedings of Conference on QA and Student Learning Outcomes of HE in Asia-Pacific Region, Taiwan, pp. 55-72.

6) Higher Education Evaluation \& Accreditation Council of Taiwan (2008a). 2007 HEEACT annual report. Taipei: Higher Education Evaluation \& Accreditation Council of Taiwan. 